\title{
Parents' memories of having a child die in the PICU
}

Diane Yorke PhD, RN, CPNP, Clinical Assistant Professor, School of Nursing, The University Of North Carolina At Chapel Hill, North Carolina, USA

Key Words: dying * parents' experiences * paediatric intensive care * reflections *

E-mail: dyorke@email.unc.edu

\section{ESPAÑOL}

Memorias de padres de niños fallecidos en UCIP

Palabras clave

Cuidado intensivo pediátrico, experiencias de padres, muriente, reflexiones

\section{Resumen}

La mayoría de los niños que fallecen en el hospital lo hacen frecuentemente en la unidad de cuidado intensivo pediátrico (UCIP). Poco se sabe acerca de como los padres/familias recuerdan la experiencia.

Este estudio le pidió a los padres, quienes habían tenido un niño fallecido en UCIP, contar la historia de sus niños muriendo y evaluar esta experiencia usando el Cuestionario de Calidad de Agonía y Muerte.

Los hallazgos sugieren que los padres de niños fallecidos en la UCIP quieren una comunicación e información más directas acerca de la condición de sus niños; quieren permanecer presentes e involucrados en el cuidado de sus hijos; $y$, necesitan y quieren alguna forma de seguimiento en el cuidado después de que el niño ha muerto.

\section{SUMMARY}

- Most children who die do so in hospital, frequently in pediatric intensive care units (PICU). Little is known about how parents/ families remember this experience.

- This study asked parents who had a child die in one PICU to tell the story of their child's dying and to evaluate this experience using a modified form of the Quality of Dying and Death Questionnaire.

- $\quad$ Findings suggest that parents of children who die in the PICU want more direct communication and information about their child's condition; that they want to remain both present and involved in their child's care; and, that they need and want some form of follow-up care after their child has died.

\section{BACKGROUND}

Many children die in the United States (US) each year and most die in hospital settings, frequently in PICU (Angus et al., 2004). Parents' experience of their child's dying affects their evaluation of the quality of the end of life care that was provided (Meert et al., 2009). Interestingly, researchers (Shannon et al., 2002) have reported that dying patients and their families' views of what constitutes quality end-of-life care differ from those of the health care team. While the health care team frequently measures quality in the ability to prolong and extend life, patients and families more often judge the quality of care in terms of whether they experienced the delivery of care in the manner they wanted and when they needed it and whether this care added quality to their loved one's last days of living.

Most end of life care research has focused on dying adults and their families. Neither family nor health care workers expect children to die, and frequently they do not know how to approach this possibility. Physicians have been reluctant to discuss the possibility of death with patients that 'feel well' and defer these conversations until the patient is experiencing symptoms (Keating et al., 2010). Paediatricians have reported feelings of inexperience when confronted with dealing with dying children (Behnke et al., 1984; Sack et al., 1984; Yazdani et al., 2010). Despite this, families have expectations that their child's health care team will provide open communication and emotional support and comfort during, at, and following their child's dying (Harper \& Wisian, 1994).

The publication of the Institute of Medicine report When Children Die (Field \& Behrman, 2003) increased focus on the experience of having a child die and researchers have begun to seek parents' recommendations to improve or make better the bitter experience of having a child die. This study explored the experience of parents who had a child die in the PICU and their ideas for making this experience better or less agonising for others.

The Framework for a Good Death (Emanuel \& Emanuel, 1998), which describes various characteristics, dimensions, and interventions that influence the experience of dying, guided this research. According to this framework, modifiable aspects or dimensions of dying include the experience and the treatment sought and accepted for symptoms like pain, loss of appetite, and fatigue. Social relations with family and community are also thought to be modifiable characteristics, that is, patients and their families can increase or decrease their social involvement, and this in turn will shape their experience of dying and death. When a patient's condition or prognosis worsens, expectations or hope for a cure can be reframed to expectations of or hope for comfort, companionship, and closure. Often, patients at the end of life and their families try to make it to and through special anniversaries or occasions. Providing frequent communication and discussion about a child's condition satisfies parents' need to know and reduces the stress 
and anxiety of uncertainty (Hupcey \& Zimmerman, 2000; De Graves \& Aranda, 2008).

Continuing to provide support and care-giving to the child as he or she approaches death requires frequent adaptations to changes in condition and needs. The intensive care unit setting itself requires families to adapt the ways in which they parent. How information is discussed, presented, and exchanged with patients and their families has been shown to directly influence their experience (Heyland et al., 2002). Also important to patients and families is feeling that their religious and spiritual practices are recognised and valued (Robinson et al., 2006). Helping survivors and families find and articulate a sense of purpose to their loved one's life also influences how they remember the experience (Zeitline \& Harlow, 2001). Finding or establishing this sense of purpose may contribute to patients' sense of worth and help their survivors to create meaning about and around the life and death of the patient.

This study explored parents' memories of having a child die in the PICU. Participants were asked what they remembered about maintaining family roles, communicating and sharing information, controlling pain and alleviating symptoms, and receiving support from the health care team. They were then asked for their recommendations for improvement and what they considered essential to providing a good death in the PICU. Research suggests that the dying and death experience can be framed to provide memories that contribute to feeling that a good death did occur (Meyer, Ritholz, Burns, \& Truog, 2006; Pierce, 1999). Finally, this study sought to discover how parents evaluated the quality of the experience of having a child die in the PICU.

\section{SETTING}

The study was conducted in a PICU in a southeastern academic children's hospital. At the time of the study this PICU had approximately 1000 admissions per year and as in other PICUs, about $5 \%$ of admitted children die.

\section{Subjects}

Subjects were the healthy adult parents or guardians of 14 children who died in the PICU during 2004 and 2005. Participants were 2763 years of age. The ages of their children ranged from newborn to 20 years. The children spent from 6 hours to 22 days in the PICU and had been in the hospital 2 to 270 days. Four of the children who died had cancer (one aged 16, one aged 9, and two less than a year old). Five children had congenital heart disease (four died before they were two months old, and one died at 3 years following the last stage of surgical correction for her heart defect). One teenager had liver failure. Four other children died of respiratory failure due to cystic fibrosis(CF), duchenne muscular dystrophy (DMD), seizures, or recurrent pneumonia.

\section{METHODS}

The Institutional Review Board approved the study. The PICU data base was used to obtain a list of all patients who died between 01 January, 2004 and 31 December, 2005, their age, length of stay (LOS), and admitting diagnosis. All parents experiencing a child's death in the PICU during 2004 and 2005 were sent a letter informing them of the purpose of the study and inviting their participation. This invitation included a Frequently Asked Questions sheet, a contact information form, the Health Insurance Portability and Accountability Act release form (allowing review of their child's chart) and a stamped addressed envelope. Letters of invitation to the study were mailed to the last known addresses of 80 parents. Three families had no last known address or phone number and no further contact was attempted.

Nineteen letters were returned as undeliverable. Three parents declined to participate. Three parents telephoned to express their interest in participating and spoke at length about their and their child's experience in the PICU, but subsequently they were unavailable for a further interview. Eight other parents/families responded by letter agreeing to participate. A research assistant called the last known numbers for the other families, resulting in further recruitment of six other families. In all 15 interviews were conducted with 23 parents or grandparents of 14 children who died in the PICU during the study timeframe.

Parents and grandparents participated in a semi structured interview that was audio taped. During the interviews parents were asked to tell the story of how their child came to be in the PICU and what they remembered about the experience, what they would recommend for improvement and what they felt was most important to parents having a child die in the PICU. These interviews were then analysed for content and recurring thoughts and topics. Constant comparative analysis of the interviews was done to examine for unconsidered ideas or themes. Each subsequent interview was shaped in part by the interviews that preceded it.

The quantitative aspect of this study asked parents to evaluate their and their child's experience using a modified version of the Quality of Dying and Death Questionnaire (QODD). This tool has been designed for use with families of adult patients and has recently undergone further investigation and refinement (Downey et al., 2010). Permission to use and modify the tool was obtained from one of the original authors (Dr DL Patrick, personal communication, 1/4/06). The modified QODD was reviewed and discussed with three PICU nurses, one parent of a child who had died in the PICU several years before, and by comparison to the aspects of care presented in the Framework for a Good Death (Emanuael \& Emanuel, 1998).

Participants were called to arrange a convenient time to meet. Interviews were expected to last 30 to 60 minutes though at least half of the participants spoke for longer than an hour and one interview was cut off at two hours. It was expected that interviews would be conducted individually but couples/families preferred to participate together. Three mothers were interviewed individually. When parents agreed their 'story' was over or that they had nothing else to say the recorder was turned off but often parents would start talking about their child some more. Several times the researcher was at the door and leaving and parents would start again to tell more of their story. Written notes of these extended encounters were taken. After the recorder was turned off, parents were asked to use the modified QODD to evaluate the quality of their child's experience of certain aspects of care that may or may not have been provided in the PICU. The conversations that parents and families had while completing the modified QODD were not recorded but parents spoke together and conferred about what had happened and when and they asked for clarification on several of the items. Often they said they weren't going to answer an item because they didn't feel they could answer about the experience for their child. Each prior interview shaped the remaining interviews and a content analysis of the findings was conducted after all interviews were complete.

Parents' evaluation of the experience of having a child die in the PICU was determined by their completing the modified QODD. In this study the reliability of the QODD was calculated using SPSS to determine the Cronbach's alpha. The 0.929 alpha suggests the tool is a reliable indicator of the quality of dying and death, however, the very small sample size and the number of missing values suggest this alpha may not be too credible. 


\section{FINDINGS}

What do families recall about having a child die in the PICU?

When a child is admitted to the intensive care unit the ability for parents to carry out or maintain their usual parenting role is frequently impeded by the critical health care needs of their child. Most if not all of their parenting responsibilities must be surrendered to the intensive care unit staff. This often reduces their parenting role from doing for their child to observing others do for them. For parents this can be frustrating. As well, the PICU caregivers can forget that families know the child best. When parents were not included or their opinions not considered or asked for they sometimes became frustrated. As one guardian said:

- "I told them point blank, I am his grandmother... I mean I've lived with this kid for three years... he holds his breath and turns blue... and I reached over and turned him and his respirations went up. They [health care team] need to listen to the parents or the grandparents more."

Throughout the discussions about maintaining family roles parents talked of wanting to be more involved with the care of their child. These parents wanted instruction in how to provide care for their child despite the machinery and accoutrements of the intensive care environment. In maintaining their family roles the theme of communication recurred in parents' expressions of wanting to be more informed and be informed earlier of what they could do to remain providers of care for their children. The father of a teenager with cancer said,

- "I didn't know how far I could ask or was supposed to ask... [about] comfort measures. How to put powder under the arms to prevent chapping or to help when he needed to be cleaned or moved."

Other parents recalled being encouraged to participate in care and maintain their parenting roles despite the extent of technological instrumentation attached to their child. Nick and Mary were parents to an infant with a serious heart defect. Mary said: "I would just kind of move her arms and try to rub her feet... 'cause you know, with her there wasn't a lot of room that we could touch her, she was pretty much filled up from head to toe." At this point she showed a picture of her daughter intubated, cannulated for extracorporeal membrane oxygenation (ECMO), with a mediastinal and two pleural chest tubes, lined for arterial and central venous pressure (CVP) monitoring, with several other peripheral intravenous (IVs), a nasal gastric tube and a foley catheter.

Most parents and grandparents in the study reported developing excellent relationships with the different members of the health care team in the PICU. They expressed pleasure at having consistent caregivers (nurses, respiratory, chaplains, doctors). Terry described how having consistent caregivers for his son was reassuring:

- "That was his team. They had shifts so almost three or four nights a week the young man would be there and three or four days a week this same young woman would be there and ...। I was very glad to see the same person when I come in. Then I just didn't feel like they were assigning nurses to whoever's needed that time; that they have actually knowledge of his special symptoms."

Yet, relationships with the PICU health care team were strained for some parents. For one parent the first memory she shared was her feeling that the seriousness of her daughter's condition was dismissed even before the doctor examined her child or spoke with her. She recalled:

- $\quad$ "In walks Dr A with Dr B and I'm in the crib with my daughter and she is alert and not grunting anymore... But his, first words out of his mouth was 'What is she doing in here?' with kind of an attitude... He just looked at her from across the room with this, what-is-she-taking-up-my-bed-space-for?-she-doesn'tlook-sick-enough kind of attitude."

Two years after her child's dying this mom remained visibly angry at this doctor and at how nonchalant her child's condition was presented to her and her husband. Her baby died within 24 hours of admission to the PICU.

Parents most often mentioned, discussed and referred to what they were being told and how. In one interview the parents mentioned no less than 200 times the importance of how information was shared with them. These parents wanted "communication," wanted to be "told", wanted to "discuss," "know," "say," and "tell" about their child. Other parents spoke about the communication that happened or didn't happen or that they wished had happened. Almost all of the parents mentioned how at some time the information they received conflicted with other information they had been told.

Parents also looked for ways to enhance their understanding of their child's condition or treatment plans. They mentioned using the internet to look things up. But even with good knowledge and medical backgrounds they often were at a loss to understand what they were being told. Only two of the subjects reported not having finished high school and most had attended some college or graduate school. Parents didn't want information 'dumbed down' they just wanted it presented in a way that they could understand. And they wanted to be checked back with to make sure they understood or could ask questions after thinking about what they had been told.

Most of the parents in this study reported their child's pain or other symptoms were controlled. They also recalled being reassured by the manner that the health care team performed physical care. Parents were able to describe instances when pain and symptom control were provided for their child and how they were reassured their child was comfortable. They remembered staff educating them about the treatments and medicines being used to relieve their child's pain and control his or her symptoms. They were reassured by the way physical care was carried out and how gently their child was treated. One parent recalled a nurse's care:

- "She was just really gentle and she talked to her while she was doing it and that kinda helped me and made me feel more comfortable."

Another parent recalled wondering how all the treatments and equipment were affecting her daughter and asking whether she was experiencing pain:

- "And the other thing we were worried about... the possibility of the pain and her remembering it or anything like that. And the nurses would explain the drug processes and would tell us 'she is comfortable, she's not in pain.' Because when you looked at her, you know, it pained us. And, it looked painful..."

When asked about support families mentioned the availability and involvement of both the chaplaincy and the social work departments. They liked being able to spend their nights in at the McDonald House. When their child's condition was worsening they found it 
supportive to be able to stay in the family rooms just outside of the PICU. New mothers appreciated having the electric breast pump and being provided with a nursing mother's diet tray. This supported them in continuing to develop their feeling of being a mom despite not being able to directly feed or interact more normally with their newborns. Many of the parents brought their own computers in to their child's room and were able to continue to work or remain in contact with family and friends. Having a room phone also allowed them to receive outside calls and remain present with their child.

Interestingly, parents did not mention nurses or nursing when asked about support systems offered in the PICU. This might suggest that families didn't find nurses supportive. However, without fail each family mentioned how wonderful they found the nurses, how great the nursing care provided was, and what great relationships they formed with certain nurses. This finding suggests that when asked about support systems parents have a different connotation of what this means and that nurses and nursing care are not considered within this connotation. For parents, nurses and nursing care are something different and separate from support systems.

What recommendations do parents who have had a child die in the PICU make to improve this experience?

Parents recommended that communication be improved and increased both between the team and the parents but also among the different health care team members. Parents felt that more communication and more information about the seriousness of their child's condition sooner in the course of treatment may have led them to make different decisions or to have decided earlier about their child's treatment course. Parents would have liked to have been told more directly that their child was dying, was expected to or could die soon so that they might have made other arrangements. These other arrangements included being able to take their child home for some time, to do some last thing their child had wanted or requested, to have gotten to say goodbye, or to have made some kind of family memory.

Parents also recommended that some system of follow-up with the parents of children dying in the PICU be implemented. Parents in this study wanted to be called, written to, checked up on, and asked about their coping. They wanted to have been told what to expect after their child died - what feelings they might have, how they might react afterwards. Even after more than a year parents wanted to talk about their child and their experience. One parent related: "And... and there's a lot there. I mean, for fathers and especially mothers, you know? That connection with your child, and losing that child. There is - it needs to be dealt with psychologically, and people need to express their feelings, and to go through the grieving process and don't need to be shut down... Maybe after a phone call, send out a package with all types of information especially about the grieving process."

What do parents consider essential to enabling a good death for children who die in the PICU?

The parents in this study made many and varied suggestions for improving end of life care for parents of children dying in the PICU that could greatly affect how parents experience and remember this. These suggestions ranged from simply making the PICU environment more comfortable and welcoming to allowing parents more time at the bedside after their child has died. However, the one common suggestion was that communication be improved: communication of bad news and style of communication were specifically addressed by parents in this study. Parents wanted communication from the health care team to be direct, accurate, and realistic. As Mary succinctly put it: "Don't sugar coat it with me when you're talking about my boy."

\section{Other information parents shared}

Coming into the PICU was likened to stepping off of a spaceship into some alien world both foreign and frightening:

- "It's like, oh my God he's moved into the PICU... When the doctor comes by it's now more scary than it's ever been...It's like taking a huge step, a bigger step than you think it's gonna be... You need more monitoring and everything but the reason you need that is because this is really happening... Your condition has worsened... There is nothing familiar. There's nothing homey. There's nothing, it's just a different kind of place."

A lot of the technology in the PICU looks like it is from outer space. Unfortunately, intensive care hasn't progressed to look anything like health care delivered in the Star Trek series - where there were simple wands scanned over the patient curing and healing within seconds and almost always with a good outcome for the patient with little to no side effects.

Parents in this study continued to have very strong feelings (tears visible, wiping eyes and nose, having a quivering chin when talking, openly crying, speaking of post traumatic stress syndrome) about their loss and it was very obvious that they continue to miss their child deeply even though it has been more than a year after he or she has died. They were aware that their grieving was prolonged and wanted to know what normal grieving was supposed to be like. Parents invested much time and energy in attending to their child throughout the length of their illness regardless of whether the illness or condition lasted for a short or a prolonged time. When their child died these parents faced emptiness in their routine and wondered how they would continue. One mom said:

- "And the next day I think was harder on me, because I felt all the pressure I had and all the feelings I had, I was like, now what do I do? You know? I've been there for her. l've been there every day. Now what do I do?"

Several parents made comments that suggested they continue to feel some guilt at having their child die. This occurred most often with parents who withdrew life supporting technologies or who were unable to be present as their child died. Other parents regretted that there may have been something they could have done that may have improved their child's last days. One father, Terry, spoke at length about how he wished he had realised how close his child was to dying. He regretted not having been able to fulfill his son's requests to come home:

- $\quad$ "You know, he said 'I want to sit in my room one more time. I want to see my livestock... I want to ride my four-wheeler and sit in my car one more time.' And if we knew that... within seventy-two hours he was actively dying... I just wished he'd been sicker or visibly sicker to me before he moved into the ICU. Before then if we were going to move him there knowing that he was probably not going to come out, there was just several things we wished we had gotten to let him do."

Parents also spoke of the meaning their child's life has had and continued to have. They expressed interest in participating in this study to continue to give meaning to their child's life and to share their experience to make things better for others. Parents brought out pictures of, websites about, and tributes for their children. One 
mother during our interview was wearing a button pin picture of her daughter. Most parents had pictures of their child openly displayed in their homes or pulled out photos and photo albums during their interview. One parent described bringing her daughter home to hold and rock after she had died so that she would become and remain a part of the spirit of their home. Several other parents donated organs from their child.

Parents of infants who died in the PICU expressed a desire to have taken more pictures of their child especially prior to their surgeries or treatments. Photographs provide both memory and meaning to parents' experience of their child but pictures may also serve as stark reminder of all that they and their child went through.

Most parents gave examples of the meaning their child's life and death had and the contribution their child has made or was able to make on their dying. They mentioned the actions they take or would like to take to continue their child's legacy - being a representative to other parents of children with congenital heart disease, remaining in contact with their child' specialists, sponsoring fund-raising events, providing real information on a website for other parents.

How do parents of children who have died in PICU evaluate quality of dying and death in PICU?

Parents rated almost every aspect of care presented in the QODD highly. Parents' scores from this tool suggest that for the most part the quality of the dying and death for children in this PICU was acceptable. The range of scores was 4 to 10 , the mean score was 7.25 (median 7.8) and the standard deviation of scores was 2.11 $(95 \% \mathrm{Cl} \pm .91)$.

The item receiving the lowest rating from parents concerned whether their child was able to be fed or feed him/herself. Ten parents gave this item a low rating and four parents rated this item as high. Parents of infants may especially have been concerned about not being able to feed their child or having to stop breast feeding or perhaps even never having been able to actually breast feed, but this is not readily obtained from the modified QODD. There was no target question in the semi-structured interview designed to capture parents' feelings about their child's ability to eat or be fed.

When examined for whether parents reported that their child was able to be fed at least a good bit of the time, two parents reported yes and both of these parents rated their child being able to eat as low quality. Why these parents felt this way is unexplored with this tool. The modified QODD does not investigate any aspect of care for more than frequency and parents' evaluation of the quality of their experience of this aspect of care so it is difficult to say why parents would regard their child's being able to be fed or to eat as low quality.

\section{DISCUSSION}

Participants identified several needs that influence how they experienced being in the intensive care unit. Most often identified were the needs to be present, to have accurate and timely information, and to remain involved in care. When parents face the real possibility of losing their child which comes with many PICU admissions these needs are heightened. This knowledge about the needs of parents of children in PICU is not new - Kasper and Nyamathi first reported the needs of parents of children in the PICU in 1988 and more recently the needs of bereaved parents in the PICU have been examined by Meert et al. (2009). The stress experienced by parents of children in the PICU was reported by Miles as early as 1979. The findings from this study provide evidence that even though the needs of parents facing their child's death in the PICU are identified and articulated they are not being met.

\section{Limitations}

Participants self-selected into the study and the sample size is small [14 of the $83(17 \%)$ families experiencing a child's death in this PICU in 2004 and 2005].

Waiting at least twelve months after a child's death may possibly have introduced some recollection or historical bias. However, parents experiencing the death of child are reported to require at least a year of time to pass before being able to reflect back on the death (Klass, 1993, Klass, 1997). This was a one-setting study and findings may not be transferable to other PICUs in different areas or with different patient populations.

English is a second language for an increasing number of the population of this PICU and the US health care system. In this study a tenth (eight of 83) of the families experiencing their child's death in the PICU were identified as Hispanic. Excluding Spanish speaking parents limited the study results and delayed the opportunity to obtain information from these parents about how to improve care for the Spanish speaking community.

A serious limitation to these study findings is the absence of participation from parents whose child was brought to the PICU to be treated for injuries that were the result of trauma. Ten of the 84 children who died in this PICU in 2004 and 2005 were admitted for serious traumatic injuries. The experience of having a child die suddenly from traumatic injuries may be different from the experience of having a child die from other causes. Traumatic deaths of children may be unique for parents for many reasons that we don't know about. It has been suggested that parents who's child has died suddenly and traumatically may experience an extended time of grieving despite the passage of time (Hawton et al., 1998), they may have unresolved feelings about the circumstances surrounding their child's death (Klass, 1997), and they may suffer complicated grief (Meert et al., 2010). This study was unable to investigate any of these possibilities.

\section{CONCLUSIONS}

In conclusion, parents facing or having a child die in the PICU want better communication about what is happening or expected to happen with their child. This is probably true for parents dealing with a child's death in any setting but this study dealt only with parents whose children died in the PICU. How parents relate the story of their child's dying in the PICU doesn't necessarily match or coincide with how they rate the quality of the experience. For the most part the quality of any aspect of care was rated as acceptable (in this case more than 3 on a scale of 1-10), but parents discussion of different aspects of care indicate that less than satisfactory care was provided and this was especially true about how they talked about the communication and exchange of information with the health care team. In addition, parents who have had a child die in the PICU require some system of structured follow-up to deal with their memories, post-ICU stress, and grief.

\section{Implications}

Parents vividly remember their experience of having a child die. Health care providers in the PICU, most especially the nurses working there, need to restructure the PICU environment so that parents can remain present, can feel adequately and appropriately informed, and can remain involved in providing care to their child. Parents who have gone through this tragic experience have a wealth of information to share that we as nurses and health care providers can tap to improve end of life care in the PICU. Most importantly, nurses and other care providers must continue to develop their abilities to discuss and present the real possibility to parents that children who need to come into the PICU may indeed die. 


\section{Future directions}

Further work is needed to develop and implement a How to approach and involve families in discussing bad news training program for PICU and other health care providers. Also needed is development and implementation of a structured program of follow-up for parents and families of children dying in the PICU as well as to other families of dying children. Families who have experienced the death of a child should be invited to be involved in delivering follow-up program to more recently bereaved parents. The needs of non-English speaking families who have a child in PICU desperately need to be investigated. Health care providers, especially nurses need detailed education about different cultures' attitudes and behaviors about death. Finally, it is important that work continue to determine and meet needs of PICU staff for recognising and managing grief, their patients' and their own.

\section{REFERENCES}

Angus DC, Barnato AE, Linde-Zwirble WT, Weissfeld LA, Watson RS, Rickert T, et al. (2004). Use of intensive care at the end of life in the United States: An epidemiologic study. Critical Care Medicine 320, 638-643.

Behnke M, Setzer E, Mehta P (1984). Death counseling and psychosocial support by physicians concerning dying children. Journal of Medical Education 59 (11 Pt1), 906-908.

De Graves S, Aranda S (2008). Living with hope and fear -- the uncertainty of childhood cancer after relapse. Cancer Nursing 31(4), 292-301.

Downey L, Curtis JR, Lafferty WE, Herting JR, Englebuerg RA (2010). The Quality of Dying and Death Questionnaire (QODD): Empirical domains and theoretical perspectives. Journal of Pain and Symptom Management 39(1), 9-22.

Emanuel EJ, Emanuel LL (1998). The promise of a good death. Lancet 351, Supp. II, 21-29.

Field MJ, Behrman RE (Eds.) (2003). When children die: improving palliative and end-of-life care for children and their families. Washington, DC: National Academies Press.

Harper MB, Wisian NB (1994). Care of bereaved parents. A study of patient satisfaction. Journal of Reproductive Medicine 39(2), 80-86.

Hawton K, Appleby L, Platt S, Forster T, Cooper J, Malmberg A, et al. (1998). The psychological autopsy to studying suicide: A review of methodological issues. Journal of Affective Disorders 50, 269-276.

Heyland DK, Rocker GM, Dodek PM, Kutsogiannis DJ, Konopad $\mathrm{E}$, Cook DJ, et al. (2002). Family satisfaction with care in the intensive care unit: Results of a multiple center study. Critical Care Medicine 30(7), 1413-1418.

Hupcey JE, Zimmerman HE (2000). The need to know: experiences of critically ill patients. American Journal of Critical Care 9(3), 192-198.
Kasper JW, Nyamathi AM (1988). Parents of children in the pediatric intensive care unit: What are their needs? Heart and Lung 17(5), 574-581.

Katz S (2002). When the child's illness is life threatening: Impact on the parents. Pediatric Nursing 28 (6), 453-463.

Keating NL, Landrum MB, Rogers SO, Baum SK, Virnig BA, Huskamp HA, Earle CC, Kahn KL (2010). Physician factors associated with discussions about end-of-life care. Cancer 116(4), 998-1006.

Klass D (1997). The deceased child in the psychic and social worlds of bereaved parents during the resolution of grief. Death Studies 21, 147-175.

Meert K, Briller S, Schim S, Thurston C, Kabel A (2009). Examining the needs of bereaved parents in the pediatric intensive care unit: a qualitative study. Death Studies 33(8), 712-740.

Meert KL, Donaldson AE, Newth CJL, Harrison R, Berger J, Zimmerman J et al. (2010). Complicated grief and associated risk factors among parents following a child's death in the pediatric intensive care unit. Archives of Pediatric and Adolescent Medicine 164(11), 1045-1051.

Meyer EC, Ritholz MD, Burns JP, Truog RD (2006). Improving the quality of end-of-life care in the pediatric intensive care unit: Parents' priorities and recommendations. Pediatrics 117(3), 649657.

Miles MS (1979). The impact of the intensive care unit on parents. Issues in Comprehensive Pediatric Nursing 3, 72-90.

Patrick DI, Engelberg RA, Curtis R (2001). Evaluating the quality of dying and death. Journal of Pain and Symptom Management 22(3), 717-726.

Pierce SF (1999). Improving end-of-life care: Gathering suggestions from family members. Nursing Forum 34(2), 5-14.

Quality of Dying and Death Questionnaire for Family Members Version 3.2A (2002). University of Washington. Available at http:// depts.washington.edu/eolcare/instruments/familyqodd3_2.pdf Accessed May 25, 2011

Robinson MR, Thiel MM, Backus MM, Meyer EC (2006). Matters of Spirituality at the End of Life in the Pediatric Intensive Care Unit. Pediatrics 118(3), e719-e729.

Sack WH, Fritz G, Krener PG, Sprunger L (1984). Death and the pediatric house officer revisited. Pediatrics 73(5), 676-81.

Shannon SE, Mitchell PH, Cain KC (2002). Patients, nurses, and physicians have differing views of quality of critical care. Journal of Nursing Scholarship 34(2), 173-179.

Yazdani S, Evan E, Roubinov D, Chung PJ, Zeltzer L (2010). A longitudinal method of teaching pediatric palliative care to interns: Preliminary findings regarding changes in interns' comfort level. Palliative and Supportive Care 8, 35-40.

Zeitlin S, Harlow I (2001). Giving a voice to sorrow: Personal responses to death and mourning. New York: Perigree. 